International Journal of Child, Youth and Family Studies (2011) 1 \& 2: 36-64

\title{
PRE/PERINATAL ADVERSITIES AND BEHAVIOURAL OUTCOMES IN EARLY CHILDHOOD: PRELIMINARY FINDINGS FROM THE VANCOUVER LONGITUDINAL STUDY
}

\author{
Patrick Lussier*, Stacy Tzoumakis, Ray Corrado, Pratibha Reebye, and Jay Healey
}

\begin{abstract}
Several pre/perinatal factors (e.g., birth complications, maternal substance use, low birth weight) have been associated with early neuropsychological deficits and negative behavioural outcomes in infancy, childhood, and adolescence. The current study examines the relationship between maternal substance use during pregnancy and its impact on physical aggression and sexual behaviours in a sample of preschoolers. This study is based on a sample of children $(n=129)$, boys and girls, recruited as part of the KD-BEAR project, an ongoing longitudinal study conducted in Vancouver, British Columbia, Canada. The sample consisted of clinical referrals for an externalizing disorder and children recruited in daycares located in at-risk neighbourhoods. Semistructured interviews were completed with the primary caregiver. A series of structural equation modelling showed that children showing higher levels of physical aggression and sexual behaviours were more likely to have been exposed to maternal substance use and pregnancy-related complications. Implications of the study are discussed in light of the scientific literature on the early prevention of aggression and violence.
\end{abstract}

Keywords: physical aggression, normative sexual behaviours, prenatal, perinatal, early childhood, maternal substance use, birth complications, maternal distress

*Contact information: Patrick Lussier, Ph.D. is Associate Professor, School of Criminology, Simon Fraser University (SFU), 8888 University Drive, Burnaby (British Columbia), Canada, V5A1S6, Phone: 778-782-3018, E-mail: plussier@sfu.ca

Stacy Tzoumakis and Jay Healey are Ph.D. candidates at SFU.

Ray Corrado, Ph.D. is a Professor in the School of Criminology at SFU.

Pratibha Reebye, MB, BS, DPM, MRC (Psych) is Infant Psychiatrist at the British Columbia Children's Hospital and Clinical Professor in the Department of Psychiatry at the University of British Columbia. 
The period of adolescence has long been a focal point for researchers interested in the aetiology and the prevention of youth violence. In recent years, developmental psychologists have stressed the importance of looking earlier in the development to better understand: (a) the course of aggression and violence from infancy to adulthood (e.g., Tremblay et al., 1999); and (b) the risk and protective factors associated with its course (e.g., Tremblay et al., 2004). Key to this issue is the early identification of intervention targets to inform developmental prevention programs aiming to reduce the likelihood of serious forms of aggression and violent behaviours (e.g., robbery, assault, rape, homicide) before their occurrence in adolescence (e.g., Elliott, 1994; LeBlanc \& Fréchette, 1989). Longitudinal studies have contributed to an understanding of the unfolding of aggression and violence from its onset in infancy to early adulthood. These studies have shown the presence of different courses of aggressive behaviours during that period characterized by much between-individual differences and within-individual changes over time in the frequency of aggression. Of importance, these longitudinal studies have shown, first, much stability in between-individual differences as to the level of aggression in youth, and second, significant within-individual changes in the level of aggression as children age (e.g., Nagin \& Tremblay, 1999). More to the point, if the majority of children tend to manifest some level of aggression during early childhood, most learn to inhibit these manifestations before school entry. A small sub-group of children, however, that continue to be physically aggressive after school entry has been identified in different empirical studies conducted in various countries (Broidy et al., 2003). These aggressive children are often those exposed to more biosocial adversities frequently starting at the pre/perinatal period of development (Tremblay, 2003). Studies have also shown that this small group of children is at risk of a series of negative outcomes in adolescence, more specifically juvenile delinquency and various forms of violent behaviour (Brame, Nagin, \& Tremblay, 2001; Broidy et al., 2003).

Loeber and colleagues (Loeber \& Hay, 1997; Loeber \& Stouthamer-Loeber, 1998) argued that physically aggressive children follow a specific developmental pathway which, if it persists over time, escalates to more serious acts of violence, including sexual assault. Theoretical models of persistent antisocial and aggressive behaviours suggest that problems and difficulties in one life domain (i.e., interacting prosocially with peer-age group) may in fact spill over into other life domains (Moffitt, 1993). The sexual development of aggressive youth has been focused on the period of adolescence. In fact, clinical research has been concerned with the co-occurrence of antisocial behaviours with noncriminal sexuality (Figueredo, Sales, Russell, Becker, \& Kaplan, 2000), mating efforts (Rowe, Vazsonyi, \& Figueredo, 1997), risky sexual behaviours (LeBlanc \& Bouthillier, 2003) and sexual coercion (e.g., Knight \& Sims-Knight, 2003) in youth. While these sexual manifestations characterize the period of adolescence, not much is known about manifestations in childhood, especially early childhood. Childhood is an important developmental period for sexual development but has not been subject of much empirical research (e.g., DeLamater \& Friedrich, 2002; Friedrich, Grambsch, Broughton, Kuiper, \& Beilke, 1991), even less so for physically aggressive children. A recent study (Lussier \& Healey, 2010) has shown much overlap between the level of physical aggression and the level of sexual behaviours manifested by preschoolers. In other words, the most physically aggressive preschoolers tend to also be the ones showing higher levels of sexual behaviours in early childhood. In fact, male preschoolers, coming from low-income family environments and having been clinically referred for an externalizing spectrum disorder, were more likely to show elevated levels of both physical aggression and sexual behaviours. These researchers hypothesized that the co-occurrence of these two behavioural manifestations might be indicative 
International Journal of Child, Youth and Family Studies (2011) 1 \& 2: 36-64

of common developmental risk and protective factors present at the earliest developmental stages. The current study builds on these findings by examining pre/perinatal risk factors and their association with the level of physical aggression and sexual behaviours in a small sample of vulnerable preschoolers.

\section{Theoretical Framework}

Traditionally, theoretical models of aggression and violent behaviours have focused on individual-level factors and environmental-level factors. Some theoretical models have stressed the predominant role of individual-level causal factors, others the predominant role of environmental-level causal factors, while some models have stressed the interplay between the two. In the past two decades, there has been increased attention by developmental psychologists and criminologists to the possible role of a third causal pathway leading to aggression and violent behaviours. This third causal pathway has been described as the risk factors the fetus is exposed to in utero (i.e., prenatal adversities) as well as those the child is exposed to around the time of birth (i.e., perinatal adversities). Pre/perinatal adversities have been increasingly included in developmental models of aggressive and violent behaviours. Indeed, the role of pre/perinatal adversities on aggressive and violent behaviours has been recognized by risk factors studies and later introduced to contemporary explanatory models (Loeber, Slot, \& Stouthamer-Loeber, 2008; Moffitt, 1993). Generally speaking, three broad categories of pre/perinatal risk factors have been considered: (a) pregnancy-related complications, (b) birth-related complications, and (c) maternal use of teratogenic agents. These three sets of adversities have been linked to negative behavioural outcomes in childhood, adolescence, and adulthood. Pregnancy-related complications is a generic term which has been used to describe a series of medical problems which include gestational diabetes, hypertension, pre-eclampsia, placenta previa, vaginal bleeding, anemia, excessive vomiting, fibroids, etc. Similarly, birth- and delivery-related complications describe a series of medical problems including preterm delivery, fetal distress, preterm rupture of membranes, abnormal presentation, prolonged labour, umbilical cord prolapse or compression, low birth weight, etc. While the causal pathways describing how these risk factors may be linked to later negative behavioural outcomes remain elusive and speculative, the empirical association found across studies warrants further examination.

The role of pre/perinatal factors on the development of aggression and violence has been stressed in the life-course persistent theory by Moffitt (1993). According to this model, pre/perinatal risk factors impacting neural development can lead to neuropsychological deficits in the child, more specifically, verbal and executive function deficits. Moffitt argued that such deficits may be too subtle to be clinically detected and treated resulting in a series of manifestations such as poor cognitive abilities, self-regulation abilities, and a difficult temperament, all of which are precursors and risk factors of antisocial behaviour and delinquency. These manifestations, in turn, can evoke negative and even hostile reactions from the environment, and most importantly the parents, further reinforcing the negative behavioural pattern emerging (See also, Thornberry, 2005). Moffitt further claimed that the source of neuropsychological deficits tends to co-occur with a criminogenic family environment characterized by disadvantages and/or deviance. This model stresses that successive interactions between a child with neuropsychological deficits and a criminogenic environment would contribute to maintaining such early deficits. As a result, vulnerable children affected by pre/perinatal risk factors are disproportionally found in environments that will not moderate the 
International Journal of Child, Youth and Family Studies (2011) 1 \& 2: 36-64

impact of these risk factors. Brennan, Grekin, and Mednick (2003) further elaborated on other possible moderators in the relationship between pre/perinatal risk factors and aggression.

Brennan et al. (2003) raised three complementary hypotheses stipulating how the child's gender could play a moderating role:

1. Boys and girls might be affected differently by pre/perinatal risk factors.

2. There might be gender differences in the impact of pre/perinatal risk factors based on the timing of the exposure to the risk factor due to the slower brain development of males as opposed to females.

3. There might be gender differences as to the negative outcomes associated with pre/perinatal risk factors (e.g., physical aggression for boys, relational aggression for girls).

The role of child gender as a moderator is further reinforced by the observation that females learn more quickly to regulate their emotions and their disruptive behaviours (Tremblay, 2003). Taken together, it is suggested that pre/perinatal risk factors might lead to aggressive behaviours in early childhood, but this pattern might only affect children exposed to socially disadvantaged family environments and might take different forms for boys and girls.

\section{Pregnancy- and Birth-Related Complications and the Child Psychosocial Development}

Pregnancy- and birth-related complications are associated with several negative outcomes for infants and children in such areas as cognitive ability, executive function, and sensory issues. A retrospective study of 152 mothers of preschool boys and girls examined the relationship between perinatal problems and sensory integration issues (Crepeau-Hobson, 2009). This author found that gestational age (low birth weight, prematurity), psychosocial events (maternal stress, pregnancy planning), delivery complications (presentation direction, type of anesthesia), and teratogenic stress (alcohol and cigarette use) were associated with sensory processing difficulties, although the explained variance remained low (2\% to $8 \%$ ). Preterm births have been associated with several negative outcomes in the literature, including executive function deficits in infants. One study compared the executive function between very preterm infants (37 boys and girls) and healthy full term infants (74 boys and girls) matched for age and gender (Sun, Mohay, \& O’Callaghan, 2009). Results indicated that preterm infants did not perform as well on the executive function tasks of working memory, inhibition to distraction, and planning. Moreover, preterm births have been found to be more problematic for boys than for girls. Using a prospective cohort of 754 preterm boys and girls, Spinillo et al. (2009) found that risk of neurodevelopment impairment of boys was higher than that of girls at age 2. This was especially the case for those whose mothers suffered from pre-eclampsia, medically indicated preterm births, and for low birth weight infants.

When a cohort of very low birth weight infants, who were matched with normal birth weight children, were followed up to age 8, the very low birth weight children continued to display cognitive, educational, and behavioural deficits (Anderson \& Doyle, 2003). Other studies have found a relationship between obstetric complications and autism by comparing children with autism with their non-affected siblings. A population study compared children with autism $(n=465)$, their siblings $(n=481)$, and a control groups from the general population $(n=1,313)$ 
International Journal of Child, Youth and Family Studies (2011) 1 \& 2: 36-64

and found that those with autism were more likely to have experienced several birth- and pregnancy-related complications including threatened abortion, epidural use, labour induction, fetal distress, and elective or emergency caesarean delivery (Glasson et al., 2004). Researchers have also examined the question by considering the proportion that a pregnancy is free of complications (optimality) and have found an association between autism and birth and pregnancy complications (Bolton et al., 1997; Lord, Mulloy, Wendelboe, \& Schopler, 1991). One such study compared 78 children with autism and 88 of their unaffected siblings using a composite scale of 61 different obstetric complications. The authors found that those with autism had more complications during pregnancy and that the proportion of relatives with autism was not significant (Zwaigenbaum et al., 2002).

Other studies have examined the impact of birth- and pregnancy-related complications on aggression and delinquency. Severe pregnancy (physical, social, or psychological problems) and delivery complications (breech presentation, caesarean section, hospitalization of the mother or child due to lack of oxygen, blood transfusion, or jaundice) were found to be significant risk factors for parental reporting of both aggressive and delinquent behaviour at ages 10 to 12 (Buschgens et al., 2009). When looking at low birth weight specifically, mixed results have been found. Very low birth weight (less than 1,501 grams) was significantly associated with attention problems and aggression at ages 7 to 8 in a sample of 243 children (Sykes et al., 1997). Tibbetts and Piquero (1999) examined the relationship between the early onset of offending with low birth weight (less than 6 pounds), socioeconomic status, disadvantaged environment, and family structure in a sample of 207 male and female offenders. The authors found that those with low birth weight did have an earlier onset of offending, as did the interaction between low birth weight with both socioeconomic status and weak family structure. Others have found no association between low birth weight (less than 2,500 grams) and juvenile offenders (at least one conviction) or chronic juvenile offenders (five or more convictions) for any crime in a retrospective birth cohort identified using birth and justice datasets (Conseur, Rivara, Barnoski, \& Emanuel, 1997).

Contradictory results have also been found regarding birth- and pregnancy-related complications with antisocial behaviour in adulthood. One study which examined individuals with schizophrenia, found no relationship between pregnancy (e.g., pre-eclampsia, eclampsia, diabetes, fever, bleeding, Rh incompatibility, anemia) and neonatal complications (e.g., convulsions, intraventricular hemorrhage, abnormal neurological signs) with general or violent convictions at ages 35 to 44 in a sample of 636 individuals (Cannon et al., 2002). Another study found that obstetric complications alone had no effect on the risk of offending (at least one criminal conviction by age 30) in a sample of 7,101 men and 6,751 women (Hodgins, Kratzer, \& McNeil, 2001). However, the authors did find an interaction effect between pregnancy complications (such as vaginal bleeding, placenta previa, pre-eclampsia, hypothyroidism, diabetes, viral infections, smoking and alcohol consumption, hyperemesis, etc.) and inadequate parenting (reported by child welfare) and offending (Hodgins et al., 2001).

\section{Prenatal Risk Factors of Adverse Fetal and Child Psychosocial Development}

Maternal Smoking. Teratogens are environmental agents (such as nicotine, alcohol, soft drugs, and hard drugs) that can affect the fetus during the prenatal period. It has been suggested that maternal smoking causes fetal hypoxia (i.e., deprivation of oxygen to the fetus), which has a negative impact on the physical and cognitive development of the fetus (Lassen \& Oei, 1998). 
International Journal of Child, Youth and Family Studies (2011) 1 \& 2: 36-64

As such, newborns having been exposed to daily maternal smoking have been shown to be lighter and shorter (Fox, Sexton, \& Hebel, 1990; Hardy \& Mellits, 1972; Wingerd \& Schoen, 1974), as well as showing lower cognitive scores on reading, memory, spelling, and verbal comprehension tests in early childhood (Cornelius, Ryan, Day, Goldschmidt, \& Willford, 2001; Davie, Butler, \& Goldstein, 1972; Fried, O’Connell, \& Watkinson, 1992; Martin, Dombrowski, Mullis, Wisenbaker, \& Huttunen, 2006; Sexton, Fox, \& Hebel, 1990). The extent of these differences is difficult to determine considering important methodological differences in measurement and research designs across studies.

Daily maternal smoking during pregnancy has been shown to have adverse behavioural outcomes such as early disruptive behaviours (Fergusson, Horwood, \& Lynskey, 1993), conduct disorder (Fergusson et al., 1993; Weissman, Warner, Wickramaratne, \& Kandel, 1999), attention-deficits (Fergusson et al., 1993), negative emotionality (Martin et al., 2006), and aggression (Martin et al., 2006; Tremblay et al., 2004). Threshold effects appear to be at play for maternal smoking as these negative outcomes are generally found for heavy smoking, which has been measured differently across studies (e.g., >6, >10, >20 cigarettes, daily). The effect of maternal smoking remained after controlling for possible confounding factors such as the child's gender and ethnicity, maternal age, education, psychiatric diagnosis, and postnatal smoking (e.g., Fergusson et al., 1993; Weissman et al., 1999), thus suggesting that heavy smoking has a teratogenic effect. Women who tend to continue smoking during pregnancy are typically (a) younger and found in single-parent families, (b) heavy smokers, or (c) from lower educational background (Cnattingius, Lindmark, \& Meirik, 1992; Fried, Watkinson, Dillon, \& Dulberg, 1987; Pickett, Wakschlag, Dai, \& Leventhal, 2003). They are also susceptible to experience depression during pregnancy and express defiance over their right to continue smoking while being pregnant (Nichter et al., 2007).

Maternal Alcohol Use. Fetal alcohol syndrome (FAS) has been recognized for some time now (e.g., Jones \& Smith, 1973) and its teratogenic effect is well established in laboratory studies conducted on animals (Randall \& Taylor, 1979). Researchers have emphasized the longterm negative role of maternal alcohol use on the child's development of executive functions, more specifically for future-oriented behaviours such as response inhibition, planning, and regulation (Connor, Sampson, Bookstein, Barr, \& Streissguth, 2000). The negative impact of maternal substance use on the child's development, however, is multifaceted. The Seattle Prospective Longitudinal Study on Alcohol and Pregnancy, launched in 1974, has documented the associated aversive consequences of maternal alcohol use and the child's development from birth to age 25 (Streissguth, Barr, \& Sampson, 1990; Streissguth, Barr, Sampson, \& Bookstein, 1994; Streissguth, 2007). In this study, regular maternal alcohol use has been related to birth complications and lower birth weight. Adverse consequences were also found during preschool years, as regular alcohol use was linked to lower scores on a general intelligence measure, poorer attention span, and goal directedness. At school, during early and middle adolescence, children exposed to alcohol had more learning problems, attention deficits, lower reasoning skills, antisocial behaviours, and delinquency, as well as alcohol use and abuse (Carmichael Olson et al., 1997). These effects remained after controlling for potential confounding risk factors. By age 25, those having been exposed in utero to regular alcohol use were three times more likely to show characteristics of an antisocial personality disorder. 
International Journal of Child, Youth and Family Studies (2011) 1 \& 2: 36-64

Maternal Drug Use. Researchers have most often examined the maternal use of cocaine and marijuana. Cocaine use impacts the neurotransmitter systems (e.g., dopamine, norepinephrine) by blocking the re-uptake of these neurotransmitters leading to neurochemical magnification of the pleasure response and stimulating behavioural arousal (Frank, Bresnahan, \& Zuckerman, 1996). Maternal cocaine use during pregnancy has also been found to have subtle negative impacts on emotional and behavioural regulation in infants and children. Empirical studies have shown that maternal cocaine use is related to higher reactivity and lower ability to regulate anger in infants (Eiden et al., 2009) as well as higher impulsivity and poor inhibitory controls (Bendersky \& Lewis, 1998; Bendersky, Gambini, Lastella, Bennett, \& Lewis, 2003), increased frustration and disruptive behaviour (Dennis, Bendersky, Ramsay, \& Lewis, 2006), and aggression (Bendersky, Bennett, \& Lewis, 2006) in preschoolers. Maternal use of cocaine has also been linked to lower birth weight and increased risk for prematurity after adjusting for potential confounding factors (Frank et al., 1996).

Regular marijuana use has also been linked to a small but significant decrease in birth weight (Fergusson, Horwood, \& Northstone, 2002; J. Martin, Barr, D. Martin, \& Streissguth, 1996; see, however, Richardson \& Day, 1991). Richardson and Day (1994) found that maternal marijuana use was inversely linked to a measure of global intelligence. These results, however, were not replicated by Fried, Watkinson, and Gray (1998) who argued that the impact of marijuana use might be more specific to executive function tasks requiring impulse control. In that regard, regular maternal use of marijuana during pregnancy was also related to impulsive/hyperactive behaviours as well as a decreased ability to sustain attention in 6 year olds (Fried, Watkinson, \& Gray, 1992). The impact of regular marijuana use on attention deficits was also found in adolescents (Fried, Watkinson, \& Gray, 2003). Furthermore, the use of cannabis during pregnancy has been related to early behavioural problems, but this effect disappeared after controlling for post-natal exposure to aggression at home (O’Connell \& Fried, 1991). Maternal use of drugs during pregnancy tends to be more prevalent in younger, less educated, single-parent families with a lower socioeconomic background (Richardson \& Day, 1991; Fried, Watkinson, \& Gray, 1992; Streissguth et al., 1991). The teratogenic effect of a specific drug is difficult to isolate considering that: (a) a high proportion of cannabis smokers also smoke nicotine during pregnancy, as reported by Fergusson et al. (2002); and (b) drug users are also likely to report the use of alcohol during pregnancy (Bendersky et al., 2006; Streissguth et al., 1991).

\section{Aim of the Study}

Theoretical formulations of general antisocial behaviours - in particular, aggression and violent behaviours - have stressed the contributing role of pre/perinatal factors. The aims of the study are threefold. The study aims to examine the association between early exposure to adversities during pregnancy and birth and later behavioural outcomes. More specifically, the study investigated whether pre/perinatal risk factors such as the maternal use of alcohol, drugs or nicotine, or pregnancy-related and birth-related complications, are associated with higher levels of physical aggression and sexual behaviours in preschoolers. Considering that prior studies have shown the co-occurrence of higher levels of physical aggression and sexual behaviours, the study also investigated the possibility that both of these phenomena might share similar risk factors. 


\section{Methodology}

\section{Sample}

The study is based on the first 129 children (boys, girls) recruited as part of the Vancouver Longitudinal Study on the Psychosocial Development of Children (KD-BEAR Project) conducted in Vancouver, British Columbia (B.C.), Canada. The KD-BEAR (i.e., Kids' development of behavioural, emotional and aggression regulation) is an ongoing longitudinal project that aims to inform policy-makers about the key early risk and protective factors for aggression and violence from the earliest developmental periods. This project was initiated by the B.C. Ministry of Children and Family Development and the B.C. Ministry of Health, in collaboration with researchers affiliated with the B.C. Children's Hospital and the School of Criminology at Simon Fraser University. All children included in the study were recruited between February 2008 and April 2009. Two samples were recruited for this study. First, a clinical sample $(n=17)$ was recruited at the Infant Psychiatric Clinic at the B.C. Children's Hospital. Clinical practitioners informed the primary caregiver about the KD-BEAR project. The inclusion criteria were as follows:

1. The child is currently being assessed and/or treated for any externalization spectrum disorder.

2. The child is between 3 and 5 years old.

3. Both the child and the primary caregiver have a reasonable understanding of English.

4. The child and the primary caregiver reside in and around the city of Vancouver and the Greater Vancouver Regional District (GVRD).

For the majority of this sample, concern over the child's aggressive behaviour was one of the main reasons cited for referral to the clinic for assessment or treatment. Based on the clinical assessment conducted at the clinic, this sample of children was mainly characterized by Attention Deficit Hyperactivity Disorder and Oppositional Defiant Disorder. 
International Journal of Child, Youth and Family Studies (2011) 1 \& 2: 36-64

Table 1. Descriptive information for the sample of preschoolers $(n=129)$

\begin{tabular}{|c|c|c|}
\hline $\begin{array}{l}\text { Pre/perinatal } \\
\text { risk factors }\end{array}$ & Prevalence (\%) & $\begin{array}{l}\text { Descriptive statistics } \\
\text { (Mean, } S D \text {, range) }\end{array}$ \\
\hline 1. Maternal substance use & 10.9 & - \\
\hline Nicotine (at least 1 pack a day) & 3.9 & \\
\hline Alcohol (at least 4 drinks at one time) & 3.9 & \\
\hline Non-prescribed soft drugs (weekly basis) & 6.2 & \\
\hline Non-prescribed hard drugs (exposure) & 3.9 & \\
\hline 2. Pregnancy complications & - & $(M=.51 ; S D=.69 ;$ Range $=0-2)$ \\
\hline Vaginal bleeding & 12.4 & \\
\hline Anemia & 11.6 & \\
\hline Maternal serious health problems & 5.4 & \\
\hline High blood pressure (eclampsia) & 3.1 & \\
\hline Other & 20.2 & \\
\hline \multicolumn{3}{|l|}{ 3. Low birth weight } \\
\hline$\leq 5 \mathrm{lbs}$ & 7.0 & \\
\hline$>$ 5lbs & 93.0 & \\
\hline \multicolumn{3}{|l|}{ 4. Premature birth } \\
\hline$<37$ weeks & 10.9 & \\
\hline$\geq 37$ weeks & 89.1 & \\
\hline 5. Birth complications & - & $(M=.51 ; S D=.75 ;$ Range $=0-2)$ \\
\hline Signs of fetal distress during labour & 20.2 & \\
\hline Baby placed in an incubator & 12.4 & \\
\hline Cord around neck & 10.1 & \\
\hline Required oxygen & 6.4 & \\
\hline Other & 16.3 & \\
\hline
\end{tabular}

Second, the research program also includes a community sample $(n=112)$ for comparative purposes. The community sample was recruited in at-risk neighbourhoods in the city of Vancouver and the GVRD. More specifically, the recruitment took place in seven cities and in each of these cities, neighbourhoods ranked in lowest $25 \%$ by two provincial surveys were selected (Kershaw, Irwin, Trafford, \& Hertzman, 2005). These surveys rank the neighbourhoods according to various indicators related to the socioeconomic status of the family and the psychosocial development of preschoolers. Based on the survey results, we established a catchment area of daycares in at-risk neighbourhoods. Local managers of community daycares were contacted to participate in the study. In each of the participating daycares, the research team put up posters informing parents about the study. The inclusion criteria were similar for the community and the clinical samples with the exception that having been referred for an externalizing spectrum disorder was not a requirement for the community sample. It is important to stress the fact that the neighbourhoods, not the families or the children, were sampled for the study. It was expected therefore that, in spite of targeting at-risk neighbourhoods, the community sample would still provide a reasonable range of families in terms of risk factors (low-risk, medium-risk, high-risk). Descriptive information for the two samples is presented in Table 1. Only one significant difference (i.e., child's age) emerged between the clinical and the 
International Journal of Child, Youth and Family Studies (2011) 1 \& 2: 36-64

community samples, but a few more were marginally significant. The clinical sample included older children. There were also non-significant trends suggesting that the clinical sample included more males coming from single-parent, low income families with a lower educational achievement.

\section{Procedures}

The present study is focused on the first wave of data. One in-person interview was conducted with each of the research participants. Simultaneous interviews with the primary caregiver and the child were conducted as part of wave one of the data collection. The vast majority of primary caregivers interviewed were the biological mothers of the children (88.4\%). On average, the primary caregiver interview lasted about two and a half hours. The interview protocol was standardized across research participants and the data was collected using a computerized questionnaire. The child interview protocol was also standardized and lasted between 45 and 90 minutes. The interview protocol included a series of tasks and tests to assess the child's cognitive and self-regulation abilities. Both the primary caregiver interview and the child interview were conducted by trained research assistants. For the current study, only data gathered from the primary caregiver interview were used. The study was conducted according to the ethical guidelines set by Simon Fraser University, the University of British Columbia, and the B.C. Children's Hospital. Participation in the study was voluntary and the participants were informed that they could withdraw from the study at any time. The primary caregivers were paid $\$ 40$ for their participation in the study. They all signed a consent form indicating that the information was confidential and collected for research purposes only.

\section{Measures}

Environmental Covariates. Several environmental covariates were included in the study to explore possible individual differences in the level of aggression and sexual behaviours. Two sets of characteristics were examined. First, child characteristics included four general individual characteristics: (a) gender ( $0=$ male, $1=$ female); (b) age (i.e., coded as the child's age at the time of the interview; (c) ethnic origin ( 0 = Caucasian; 1 = non-Caucasian); and (d) sample, (i.e., whether the child was a clinical referral or recruited from the community; $0=$ clinical, $1=$ community). Second, we also included structural variables representing socio-demographic characteristics of the family environment. Structural variables reflecting economic deprivation or familial adversities have been related to higher levels of aggression manifested by children. Therefore, in keeping with the previous work of Tremblay et al. (2004) and Côté, Vaillancourt, LeBlanc, Nagin, and Tremblay (2006), among others, we included three items reflecting such adversities. Low family income referred to whether the family had been on welfare in the past year $(0=$ not on welfare, $1=$ on welfare). Lower parental education refers to the highest education level of achieved by the primary caregiver $(0=$ post-secondary education, $1=$ high school diploma or less). Moreover, a variable reflecting the family structure was included. The variable was coded to highlight whether or not single parenthood reflected the family structure of the child $(0=$ not in a single parenthood situation, $1=$ single parenthood $)$.

Pre/perinatal Risk Factors. Pregnancy-related complications refer to risk factors present during the gestation period. The following six indicators represent pregnancy-related complications in the current study: vaginal bleeding, anemia, serious maternal health problems, high blood pressure (eclampsia), Rh factor incompatibility, pregnancy-related diabetes. All of the 
pregnancy-related complications were dummy coded and then scored using a three-point scale: (0) absence of pregnancy-related complications; (1) presence of a least one complication; and (2) at least two complications. A higher score, therefore, reflects a higher-risk pregnancy. Birthrelated complications refer to complications occurring during delivery or at the time of birth. Birth-related complications include the following five indicators: the use of forceps, signs of fetal distress during labour, umbilical cord around the neck, baby required oxygen, and baby placed in an incubator. All of the birth-related complications were dummy coded and then scored using a three-point scale: (0) no birth-related complication; (1) presence of a least one complication; and (2) at least two complications. A high score on this scale is said to represent a higher-risk birth. Low birth weight refers to the child's weight at the time of birth. Low birth weight reflects the presence of a child weighing five pounds or less (2,268 grams or less) at birth. Birth weight in pounds (rather than grams) was used for this study to facilitate memory recall. In total, $7.0 \%$ of the sample had a low birth weight. In 2007, the provincial rate in B.C. of low birth weight (less than 2,500 grams) was 5.7\%. Premature birth (preterm birth) refers to the birth of a child of less than 37 weeks of gestational age. According to this definition, our sample included $10.9 \%$ born prematurely. By comparison, the prevalence of preterm pregnancy in B.C. in 2007 was 7.5\%. We also examined the maternal age at the time of her child's birth: (0) mother at least 21 years old, (1) mother less than 21 years old. The descriptive information for each of the pre/perinatal risk factors is presented in Table 1.

Maternal Substance Use. Four substance types were used for this study: (a) nicotine, (b) alcohol, (c) soft drugs, and (d) hard drugs. For this study, the maternal behaviours were defined as follows. First, regular use of tobacco/nicotine was defined as having smoked at least a half a pack of cigarettes per day (i.e., minimum ten cigarettes), on average, for at least one trimester of the pregnancy. In total, 3.9\% of our sample reported regular use of nicotine/tobacco during pregnancy. Alcohol use refers to having consumed, on average, at least four drinks on a weekly basis for at least one trimester. Using this definition, 3.9\% of the mothers included in the study were characterized by regular alcohol use during pregnancy. Soft drug use refers to regular use of cannabis/marijuana on a weekly basis for at least one trimester during pregnancy. Regular soft drug use during pregnancy characterized $6.2 \%$ of the mothers included in this sample. Primary caregivers were also asked to report the maternal use of hard drugs during pregnancy. For this sample, 3.9\% reported the use of hard drugs at least once during pregnancy. Crack/cocaine was the only substance reported by those having used hard drugs. For the purpose of the study, the variable maternal substance use refers to those having shown any of the previous four behaviours. In total, $10.9 \%$ of the sample reported at least one substance use corresponding to the above definitions. In order to obtain a profile of mothers having used some form of substance during pregnancy, we compared children exposed to some substance during pregnancy $(n=14)$ to those not exposed $(n=115)$ on all environmental covariates as well as pregnancy- and birthrelated complications included in the study. Clearly, several factors significantly distinguished children exposed from those not exposed to any substance. Table 2 shows that, compared to children not exposed, children having been exposed to some substance in utero were 13.4 times more likely to have a primary caregiver without a high school diploma, 6.0 times more likely to have a parent with a criminal record, and 4.2 times more likely to come from a low-income familial environment. Importantly, and in line with previous empirical investigations, these children were also 5.0 times more likely to have a low birth weight than those not exposed to any substance. 
Physical Aggression. In line with earlier studies on physical aggression in childhood (Broidy et al., 2003; Tremblay et al., 2004), three indicators were used to measure the level of physical aggression: (a) kicked, bitten, or hit anyone; (b) shoved, pushed; and (c) thrown things at other people. The primary caregiver was asked to determine the frequency of each of those four manifestations using a four-point scale: (0) never, (1) a few times, (2) several times, (3) very often. The majority of the children sampled for this study had kicked (65.9\%), shoved (68.2\%), or thrown things at someone (49.6\%) at least once in the past year. As a group, this sample of children had been physically aggressive only a few times in the past year: kicked (Mean $=1.13$, Standard Deviation $=1.00$, Range $=0-3)$, shoved $(M=1.21, S D=1.01$, Range $=0-3)$, and thrown things $(M=.81, S D=.94$, Range $=0-3)$. These averages, however, masked the fact that about one-third of our sample had, at least on several occasions, kicked (37.2\%), shoved (41.9\%), or thrown things at someone (26.4\%) in the past year.

Table 2. Overlap of pre/perinatal risk factors

\begin{tabular}{|c|c|c|c|c|}
\hline & $\begin{array}{l}\text { Exposure to } \\
\text { substance } \\
(n=14)\end{array}$ & $\begin{array}{l}\text { Not exposed to any } \\
\text { substance } \\
(n=115)\end{array}$ & $\begin{array}{l}\text { Odds } \\
\text { ratio }\end{array}$ & 95\% C.I. \\
\hline \multicolumn{5}{|l|}{ Environmental covariates } \\
\hline Presence of siblings & $9.4 \%$ & $15.2 \%$ & .58 & $.18-1.87$ \\
\hline Low income & $30.0 \%$ & $9,2 \%$ & $4.21 *$ & $.95-18.63$ \\
\hline Low parental education & $46.7 \%$ & $6.1 \%$ & $13.37 * * *$ & $3.76-47.64$ \\
\hline Parents’ criminality & $27.6 \%$ & $6.0 \%$ & $5.97 * *$ & $1.87-29.03$ \\
\hline \multicolumn{5}{|l|}{ Pre/Perinatal factors } \\
\hline Pregnancy complications & $9.5 \%$ & $11.5 \%$ & .83 & $.26-2.64$ \\
\hline Low birth weight & $33.3 \%$ & $9.2 \%$ & $4.96 *$ & $1.08-22.62$ \\
\hline Premature birth & $14.3 \%$ & $10.4 \%$ & 1.43 & $.29-7.17$ \\
\hline Birth complications & $8.7 \%$ & $12.0 \%$ & .70 & $.21-2.36$ \\
\hline
\end{tabular}

$* p<.05 * * p<.01 * * * p<.001$

Sexual Behaviours. A revised version of the Child Sexual Behaviour Inventory (CSBI) (Friedrich et al., 2001) was used to gather data on the sexual behaviours of the preschoolers. In line with Schoentjes, Deboutte, and Friedrich's (1999) findings of the factorial structure of the CSBI, three indicators were used for this study to measure the extent of the sexual behaviours: (a) touching, rubbing or masturbating, or self-directed behaviours involving the manipulation of genitals; (b) hands-off behaviours involving trying to watch people undressing, to look or try to look at people when they are nude or showing genitals to others (i.e., children, adults); and (c) hands-on behaviours which includes grabbing or touching the genitals/breasts of someone else (i.e., children, adults). These measures are not intended to be a complete examination and description of all sexual manifestations during childhood, but to represent the most commonly observed manifestations as shown by previous epidemiological studies (see, Friedrich et al., 1991; Schoentjes et al., 1999). The primary caregiver was asked to determine the frequency of each of these three manifestations using a four-point scale: (0) never, (1) a few times, (2) several times, (3) very often. In total, $74.4 \%$ of the sample reported at least one occurrence of the selfdirected behaviours in the past year, 23.3\% reported at least one occurrence of the hands-off behaviours, while 55.8\% reported at least one occurrence of the hands-on behaviours. While the 
prevalence was high, on average, the frequency of self-directed $(M=1.44, S D=1.04$, Range $=$ 0 -3), hands-off $(M=.38, S D=.79$, Range $=0-3)$, and hands-on $(M=.81, S D=.85$, Range $=0-3)$ behaviours were generally occasional.

Figure 1. Latent correlation and shared variance between physical aggression and sexual behaviours

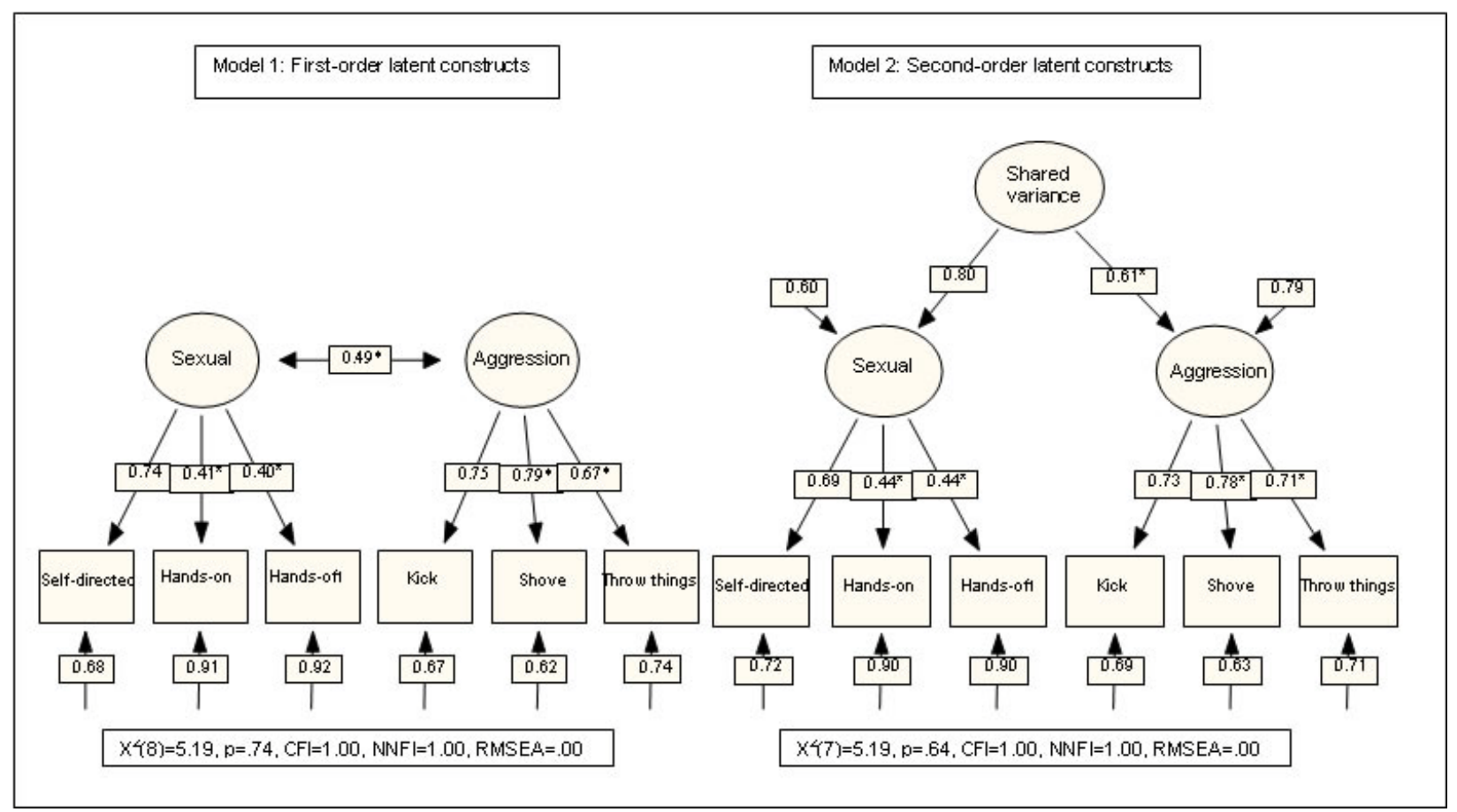

Note. $N=129$.

*All paths significant at $p<.01$.

\section{Analytical Strategy}

To analyze the covariates of aggression and sexual behaviours, we used a series of structural equation models (SEM) using EQS 6.1 (Bentler, 1995). Considering the small sample size for this study, a series of trimmed (non-nested) models were analyzed. First, we examined a baseline model including only one covariate, namely, gender. This covariate was considered a priori the single most important covariate to control for in order to avoid possible confounding factors due to gender differences between boys and girls in aggression and sexual behaviours. Hence, it was included in all subsequent models. Distinct models were successively run with each of the environmental covariates and pre/perinatal risk factors included in the study: number of siblings, low income, parent's criminal history, parental education, birth- and pregnancyrelated complications, low birth weight, premature pregnancy, young maternal age at birth, maternal emotional distress, and maternal substance use. For each of the confirmatory factor analyses (CFA) and the SEM tested, multivariate kurtosis was analyzed using Mardia's coefficient and the model's residuals were screened for the presence of model misspecifications. Also, the Comparative Fit Index (CFI), and the Root Mean Square Error of Approximation (RMSEA) were examined to determine the model's goodness-of-fit. 
Figure 2. Analytical strategy to examine the risk factors of physical aggression and sexualized behaviours and their shared variance


Note. Double headed arrows represent latent-correlations. Single headed arrows are paths. Boxes represent observed variables. Circles refer to latent variables. " $D$ " refers to disturbance while " $E$ ” to errors.

\section{Results}

\section{Specific Correlates of Physical Aggression and Normative Sexual Behaviours}

Baseline Model: Gender Differences. First, we ran a baseline model with only one covariate, the child's gender, to determine its role on physical aggression and normative sexual behaviours. The results were in line with previous investigations. Gender was related to both levels of physical aggression $(b=-.22)$ and sexual behaviours $(b=-.35)$, explaining respectively $5 \%$ and $12 \%$ of the variance. Male preschoolers were found to be more aggressive and showing more frequent manifestations of sexual behaviours than females. Of importance, the level of physical aggression and sexual behaviours did not vary across age groups (ages 3,4 , and 5 years old). Goodness-of-fit information for all the models tested in this section is reported in Table 3. 
Table 3. Latent association between environmental, pre/perinatal, individual factors and sexual, aggressive behaviours

\begin{tabular}{|c|c|c|c|c|c|c|c|c|}
\hline & \multicolumn{2}{|c|}{ Regression paths } & \multicolumn{6}{|c|}{ Model goodness-of-fit } \\
\hline & $\begin{array}{c}\text { Sexual } \\
\text { behaviours }\end{array}$ & $\begin{array}{c}\text { Physical } \\
\text { aggression }\end{array}$ & $\mathrm{X}^{2}$ & $d f$ & $\begin{array}{c}p \\
\text { value }\end{array}$ & CFI & NNFI & RMSEA \\
\hline \multicolumn{9}{|c|}{ Baseline model } \\
\hline Child's gender & $\begin{array}{c}-.35 \\
(.12)^{* *}\end{array}$ & $\begin{array}{c}-.22 \\
(.05)^{* *}\end{array}$ & 6.68 & 11 & .82 & 1.00 & 1.00 & $.00(.00-.06)$ \\
\hline \multicolumn{9}{|c|}{ Baseline model with added covariate (gender) } \\
\hline \multicolumn{9}{|l|}{ Environmental factors } \\
\hline Presence of siblings & $-.06(.00)$ & $.16(.03)$ & 9.21 & 15 & .87 & 1.00 & 1.00 & $.00(.00-.04)$ \\
\hline Low income & $.13(.03)$ & $\begin{array}{c}.25 \\
(.07)^{* *}\end{array}$ & 13.61 & 15 & .56 & 1.00 & 1.00 & $.00(.00-.08)$ \\
\hline $\begin{array}{r}\text { Low parental } \\
\text { education }\end{array}$ & $\begin{array}{l}-.02 \\
(.02)\end{array}$ & $.16(.02)$ & 10.45 & 15 & .79 & 1.00 & 1.00 & $.00(.00-.06)$ \\
\hline Parents' criminality & $.00(.01)$ & $.12(.00)$ & 9.32 & 15 & .86 & 1.00 & 1.00 & $.00(.00-.05)$ \\
\hline \multicolumn{9}{|l|}{ Pre/Perinatal factors } \\
\hline Maternal substance use & $\begin{array}{c}.27 \\
(.07)^{* *}\end{array}$ & $\begin{array}{c}.19 \\
(.02)^{*}\end{array}$ & 10.24 & 15 & .80 & 1.00 & 1.00 & $.00(.00-.05)$ \\
\hline $\begin{array}{r}\text { Pregnancy } \\
\text { complications }\end{array}$ & $.13(.06)$ & $\begin{array}{c}.17 \\
(.02)^{*}\end{array}$ & 9.38 & 15 & .86 & 1.00 & 1.00 & $.00(.00-.05)$ \\
\hline Low birth weight & $.03(.09)$ & $.06(.02)$ & 11.94 & 15 & .68 & 1.00 & 1.00 & $.00(.00-.07)$ \\
\hline Premature birth & $.01(.04)$ & $.08(.01)$ & 15.00 & 15 & .45 & 1.00 & 1.00 & $.00(.00-.08)$ \\
\hline Birth complications & $.18(.04)+$ & $.09(.01)$ & 6.76 & 15 & .96 & 1.00 & 1.00 & $.00(.00-.04)$ \\
\hline \multicolumn{9}{|l|}{ Individual factors } \\
\hline Child's age & $-.04(.12)$ & $.03(.05)$ & 10.87 & 15 & .76 & 1.00 & 1.00 & $.00(.00-.06)$ \\
\hline
\end{tabular}

Note. $N=129$. Environmental, pre/perinatal and individual factors were tested while controlling for the child's gender (see Figure 1; Model 1). The regression path is reported for each of the risk factor and the added explained variance is presented in parentheses.

${ }^{*} p<.05 * * p<.01 * * * p<.001$

Environmental Covariates. Keeping the child's gender as a covariate, we successively ran a series of models to test each of the environmental covariates and examine their association with physical aggression and sexual behaviours. Looking first at the level of normative sexual behaviours, after adjusting for the child's gender, none of the four environmental correlates examined (i.e., siblings, low income, low parental education, and parental criminality) were found to be statistically significant. Looking at the level of physical aggression, however, one of the four environmental correlates emerged as statistically significant. Low-income families $(\beta=.25)$ were found to have children with higher levels of physical aggression. That relationship was found independently of the child's gender. Taken together, the child's gender and family income explained $12 \%$ of the variance of physical aggression in preschoolers.

Pre/perinatal Risk Factors. Adjusting for the child's gender, a series of SEM analyses were conducted analyzing each pre/perinatal risk factor individually. Of the six pre/perinatal risk factors tested, only one emerged as significantly related to the level of normative sexual 
behaviours. Indeed, maternal substance use was positively and significantly related to sexual behaviours $(\beta=.27)$, thus indicating that children exposed to some substance in utero were characterized by a higher level of normative sexual behaviours in the past year. Hence, taking into account both the role of gender and maternal substance use, $19 \%$ of the level of normative sexual behaviours were explained by these two factors. Birth complications were also found to be marginally related to normative sexual behaviours $(\beta=.18)$, thus suggesting a trend for birth complications to be associated with a marginal increase in the level of normative sexual behaviours. For physical aggression, however, three pre/perinatal risk factors emerged as statistically significant after adjusting for the child's gender. Hence, more aggressive children were more likely to have been exposed to some substance in utero $(\beta=.19)$ and to pregnancyrelated complications $(\beta=.17)$. Taking into account the importance of a child's gender, the explained variance of physical aggression for these three pre/perinatal risk factors was respectively $7 \%, 7 \%$, and $14 \%$.

\section{Correlates of the Co-occurrence of Higher Levels of Aggression and Sexual Behaviours}

Baseline Model: Gender Differences. In this section we examined the role of environmental factors and pre/perinatal risk factors on the co-occurrence of higher levels of physical aggression and sexual behaviours. We first ran a baseline model with only the child's gender as a covariate to determine its role on the co-occurrence of physical aggression and normative sexual behaviours. Gender was related to the co-occurrence of physical aggression and sexual behaviours $(\beta=-.40)$, explaining respectively $16 \%$ of the variance. Male preschoolers, therefore, tended to show higher levels of both aggression and sexual behaviours than females preschoolers. Note that the co-occurrence of a higher level of physical aggression and sexual behaviours did not vary across age groups (ages 3, 4, and 5 years). The goodness-offit information for all the models tested in this section is reported in Table 4.

Environmental Covariates. Adjusting for the child's gender, we ran a series of SEM analyses and first examined the respective role of each of the environmental factors. Of the four environmental covariates examined, only one emerged as statistically significant. Hence, children showing higher levels of both sexual and aggressive behaviours were more likely to come from a low income family environment $(\beta=.29)$. Taken together, a child's gender and the family income explained $25 \%$ of the shared variance between the level of physical aggression and the level of normative sexual behaviours.

Pre/perinatal Covariates. Next, we examined the role of pre/perinatal risk factors on the co-occurrence of physical aggression and sexual behaviours. The six pre/perinatal risk factors were examined in separate analyses, always adjusting for the child's gender. Of the six risk factors examined, three were found to be statistically significant. Hence, preschoolers showing elevated frequency of physical aggression and sexual behaviours were more likely have been exposed to some substance in utero $(\beta=.32)$, more likely to be characterized by a pregnancy with complications $(\beta=.25)$. The explained variance for each of these three models ranged between $25 \%$ and $28 \%$.

Additional Analyses. A final series of analyses were conducted considering: (a) the role of low income on the co-occurrence of physical aggression and sexual behaviours; and (b) the fact that maternal substance use during pregnancy is predominantly found in lower income family environments. Therefore, we examined whether the role of maternal substance use was 
not spurious due perhaps to the confounding role of the family income. Recall here that the number of covariates analysed simultaneously is kept to a minimum due to the small sample size for the study. Hence, a three-covariate model - including child's gender, low family income, and maternal substance use - was examined, more specifically as to their role on the shared variance of physical aggression and sexual behaviours in preschoolers. The model is presented in Figure 3. Note that considering the covariance between maternal substance use and family income, both covariates were allowed to covary in this model. The model showed a very good fit of the data and explained $33 \%$ of the shared variance between aggression and sexual behaviours. The three covariates were statistically significant, and the results were in line with previous findings. Hence, male preschoolers ( $\beta=-.43)$, those from low-income family environments $(\beta=.22)$, as well as those having been exposed to some substance in utero $(\beta=.28)$ were more likely to show higher levels of both aggression and sexual behaviours. The role of maternal substance use, therefore, can't be interpreted as spurious as far as low family income is concerned, as both risk factors were found to uniquely contribute to the prediction of physical aggression and sexual behaviours.

Figure 3. Pre/perinatal factors and the co-occurrence of physical aggression and sexual behaviours

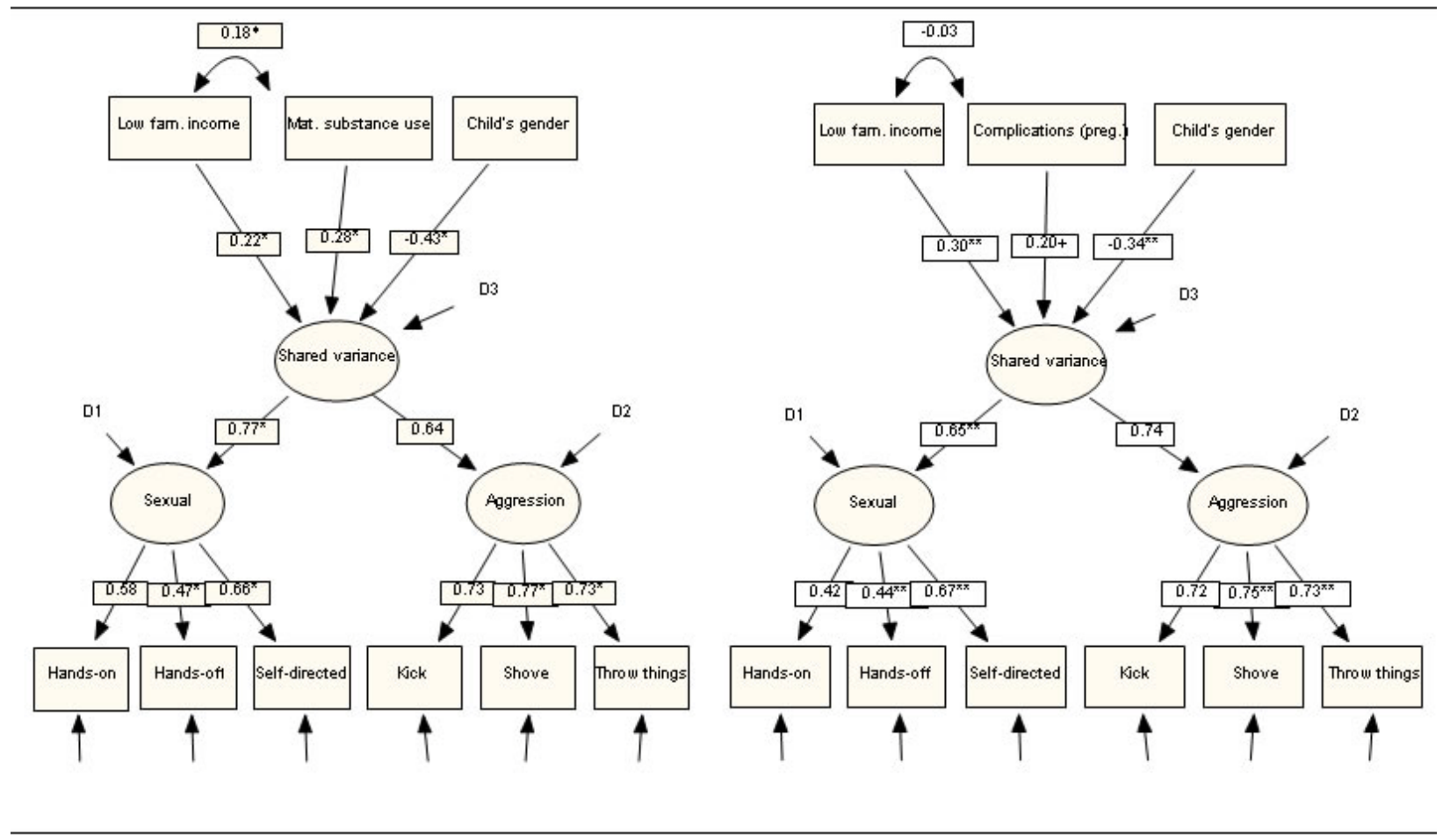

\section{Discussion}

\section{Gender Differences, Physical Aggression, and Sexual Behaviours}

Before the behaviour has been shaped by years of exposure to cultural factors, the current study reported significant gender differences in behavioural outcomes in preschoolers. Indeed, while manifestations of physical aggression and sexual behaviours were, on average, no more than occasional, the study findings also showed much variation across children. In terms of 
frequency in the past year, such variation of physical aggression and sexual behaviours were associated with gender. More precisely, the findings showed that boys were more physically aggressive and manifested more sexual behaviours than girls. In total, $5 \%$ of group differences in physical aggression and $12 \%$ of group differences in sexual behaviours were accounted for by a gender effect. Such differences have been reported elsewhere (Tremblay et al., 1999; Lussier \& Healey, 2010) and are in line with the gender asymmetry observed between boys and girls in meta-analytic reviews, especially for direct forms of aggression (Card, Stucky, Sawalani, \& Little, 2008). When physical aggression and sexual behaviours were combined into a single behavioural dimension, the gender differences were even more pronounced, suggesting that a higher proportion of boys than girls were more aggressive and sexual. When controlling for gender effects on physical and sexual behaviours, the study showed that environmental and pre/perinatal factors were statistically associated with the frequency of occurrence of these behaviours in the past year. Of importance, low family income was significantly related to physical aggression as well as the co-occurrence of physical aggression and sexual behaviours. Put differently, preschoolers of families with lower income were more aggressive and were also more likely to show higher levels of both aggression and sexual behaviours. A similar, but nonsignificant trend was also observed for parental education and the level of physical aggression. These findings replicate those observed in prior investigations showing that the most aggressive children are typically found in low income, less educated family environments (Côté et al., 2006; Lussier \& Healey, 2010; Lussier, Corrado, Healey, Tzoumakis, \& Deslauriers-Varin, 2010; Tremblay et al., 2004).

\section{Pre/perinatal Adversities and Behavioural Outcomes}

While much has been said about the individual pathway (i.e., genetic markers) and the environmental pathway (i.e., family, peers, neighbourhood) to aggression and violence, our study gives further evidence that there might be a third pathway - that is, the pre/perinatal pathway. We found small but significant associations between exposure to pre/perinatal adversities and behavioural outcomes during early childhood. The small sample combined with the low base rate of maternal use of nicotine, alcohol, and drugs did not allow the examination of the specific effects of each of these substances on the child behavioural outcomes. Hence, it is unclear whether one specific substance or polysubtance use was responsible for the statistical effects found in the study. Taking that into account, the study findings showed that maternal substance use was associated with increased levels of physical aggression and sexual behaviours in preschoolers. Furthermore, when physical aggression and sexual behaviours were forced into a single higher construct representing their co-occurrence, maternal substance use remained a significant factor. In other words, children with high levels of both aggression and sexual behaviours were more likely to have been exposed to at least one substance during pregnancy. While the association was modest ( $9 \%$ of explained variance), it was far from negligible. The effect remained significant after controlling for the only environmental factor associated with child behavioural outcomes (i.e., family income). In other words, the effect of maternal substance use on children's behaviour was found irrespective of the socioeconomic background of the family. Our findings on the teratogenic effects (Bendersky et al., 2006; Martin et al., 2006; Tremblay et al., 2004) on later behavioural outcomes replicate those reported elsewhere for aggression, but extend it to sexual behaviours and its co-occurrence with aggression. The factors influencing a mother's motives for exposing her child to teratogenic effects is unclear and could 
International Journal of Child, Youth and Family Studies (2011) 1 \& 2: 36-64

be due to: (a) a lack of understanding of the consequences of these substances on the fetus; (b) the difficulties abandoning or changing her lifestyle and/or addiction during pregnancy; (c) the self-medicating role of these substances for the pregnant mother; or (d) the result of poor decision making on the part of the mother. Part of the answer may lie in the overlap of risk factors for both the pregnant mother and her child.

\section{Overlap of Pre/perinatal Risk Factors}

Our study replicates a well-known observation that aggressive and violent youth are often characterized by a cluster of risk factors (Farrington \& Loeber, 1998; Farrington, 2005; Lösel \& Bender, 2006). From a research perspective, this complicates the task of finding the main effect of each of the risk factors present, let alone understanding how their accumulation and/or their interactions might impact the child's developmental course. Children exposed to one substance tended to be exposed to various teratogenic effects. For example, $80 \%$ of mothers who used alcohol during pregnancy also used soft drugs (as opposed to 3\% of those who did not drink); $60 \%$ of these mothers also used hard drugs at least once (as opposed to about $1 \%$ of those who did not drink); $40 \%$ of the same mothers also smoked at least one pack of cigarettes per day (as opposed to $2 \%$ of those who did not drink).

Hence, it was surprising to find that children exposed to teratogenic effects (i.e., nicotine, alcohol, drugs) were close to five times more likely to show a low birth weight $(\leq 5$ pounds). This finding replicates those observed in past studies, more specifically those having looked at the birth weight of children exposed to alcohol and drugs during pregnancy (Fergusson et al., 2002; Frank et al., 1996; Martin et al., 1996; Streissguth et al., 1990; see, however, Richardson \& Day, 1994). Although the association was not significant, low birth weight tended to be associated with increased aggression, but not increased sexual behaviours. Children exposed to teratogenic effects, were also more likely to come from a family environment with a lower income, with parents having lower educational backgrounds and a past criminal record. While our study showed that only family income was associated with increased aggression in preschoolers, others studies have shown that parents' criminality and educational background are associated with aggression in late childhood and adolescence (e.g., Farrington, 1989). Therefore, children subject to teratogenic effects are also those exposed to significant risk factors for later aggression. Economic difficulties may put more pressure on parents, thus affecting the family dynamic and family cohesion, especially for those families with a difficult child. More specifically, these at-risk children are exposed to an increasing number of risk factors as they age that can affect the course of their development in childhood and facilitate the persistence of aggressive behaviours over subsequent periods. The same may be true for sexual behaviours, but we are not aware of studies that have linked teratogenic effects to sexual behaviours in schoolaged children and adolescents.

\section{Implications}

The Vancouver Longitudinal Study is in its infancy and the study findings reported here should be considered preliminary and tentative. These findings, however, raise important issues that should be considered by both researchers and practitioners. In spite of the increased efforts of practitioners in recent years to prevent the use of teratogenic agents during pregnancy (e.g., nurses, midwives, medical doctors, and social workers), a small but significant segment of the 
population is still using nicotine, alcohol, and/or drugs on a regular basis. More importantly, mothers who use one substance tend also to use another, suggesting that polysubstance (i.e., nicotine, alcohol, soft and hard drugs) use should be emphasized in preventive efforts. Clarifying the context and the motives behind the polysubstance use during pregnancy could help inform preventive efforts. While researchers are more aware of the physical health consequences, more research is needed to better understand the behavioural outcomes. Our study suggests that the teratogenic effects are not limited to aggression, but extend to sexual behaviours. While the current study did not attempt to determine if a causal mechanism was operating, let alone determine what the causal pathway is, the findings should raise concerns for both researchers and clinicians. Among other things, the clinical assessment of preschoolers with unusually higher levels of aggression and sexual behaviours should involve the examination of exposure to teratogenic agents. Furthermore, it is not standard practice for clinicians (i.e., psychiatrists, psychologists, nurses, and practitioners) to enquire about the sexual behaviours of children referred for assessment, unless unusual sexual behaviours are atypical. Our study, and a past investigation (Lussier \& Healey, 2010) suggest that preschoolers with aggressive behaviours should also be screened for their sexual behaviours as (a) aggressive children tend to show higher levels of sexual behaviours, and (b) aggression and sexual behaviours seem to share specific correlates, such as exposure to teratogenic agents.

\section{Limitations}

The Vancouver Longitudinal Study is still in its infancy, and, as mentioned earlier, the results are preliminary. These findings should be interpreted accordingly and in light of the methodological limitations characterizing it. This study examined the sexual behaviour of children but not other important components of normal sexual development at that age, such as the sexual response (e.g., erection, orgasm) and the sexual meanings that children attribute to their response (Bancroft, 2006). We can assume that sexual behaviour, response, and meaning may be disconnected during early childhood. Also, the study was based on a small sample of preschoolers in the Province of British Columbia and, as a result, findings cannot be generalized to the larger population of Canadian preschoolers. Moreover, while the current study was based on retrospective longitudinal data, a short recall period was used to minimize poor memory recall. Furthermore, data based on only one informant (i.e., the primary caregiver) was used to measure the frequency of aggression and sexual behaviours. Consequently, some aggressive/sexual behaviours might have been overlooked, minimized, or simply not observed by the informant. Finally, because of the small sample size only a few covariates were analyzed simultaneously.

\section{Conclusion}

Several pre/perinatal risk factors have been associated with early neuropsychological deficits and negative behavioural outcomes in infancy, childhood, and adolescence. The current study replicates and extends these observations to physical aggression and sexual behaviours in preschoolers. More specifically, the study found that children who are more physically aggressive tend also to show more sexual manifestations during early childhood. The cooccurrence of these behaviours was associated, at least in part, to exposure to teratogenic effects (nicotine, alcohol, drugs) during pregnancy and pregnancy-related complications. The overlap between risk factors, especially between maternal use of any substance and family environmental 
International Journal of Child, Youth and Family Studies (2011) 1 \& 2: 36-64

risk factors suggest that as they age, physically aggressive children are exposed to an increasing number of risk factors (family income, parents' criminality, lower educational background) that may facilitate the persistence of aggression after school entry. The overlap of these risk factors may prove to be a challenge for both the aggressive child and parents trying to manage the behaviour of their child. 
International Journal of Child, Youth and Family Studies (2011) 1 \& 2: 36-64

\section{References}

Anderson, P., \& Doyle, L. W. (2003). Neurobehavioral outcomes of school-age children born extremely low birth weight or very preterm in the 1990s. JAMA: The Journal of the American Medical Association, 289(24), 3264-3272.

Bancroft, J. (2006). Normal sexual development. In H. E. Barbaree \& W. L. Marshall (Eds.), The juvenile sex offender (2nd ed., pp. 19-57). New York: Guildford.

Bendersky, M., Bennett, D., \& Lewis, M. (2006). Aggression at age 5 as a function of prenatal exposure to cocaine, gender, and environmental risk. Journal of Pediatric Psychology, 31(1), 71-84.

Bendersky, M., Gambini, G., Lastella, A., Bennett, D. S., \& Lewis, M. (2003). Inhibitory motor control at five years as a function of prenatal cocaine exposure. Journal of Developmental and Behavioral Pediatrics: JDBP, 24(5), 345-351.

Bendersky, M., \& Lewis, M. (1998). Arousal modulation in cocaine-exposed infants. Developmental Psychology, 34(3), 555-564.

Bentler, P. M. (1995). EQS: Structural equations program manual. Encino, CA: Multivariate Software, Inc.

Brame, B., Nagin, D. S., \& Tremblay, R. E. (2001). Developmental trajectories of physical aggression from school entry to late adolescence. Journal of Child Psychology and Psychiatry, 42(4), 503-512.

Brennan, P. A., Grekin, E. R., \& Mednick, S. A. (2003). Prenatal and perinatal influences on conduct disorder and serious delinquency. In B. B. Lahey, T. E. Moffitt, \& A. Caspi (Eds.), Causes of conduct disorder and juvenile delinquency (pp. 319-344). New York: Guilford.

Bolton, P. F., Murphy, M., Macdonald, H., Whitlock, B., Pickles, A., \& Rutter, M. (1997). Obstetric complications in autism: Consequences or causes of the condition? Journal of the American Academy of Child and Adolescent Psychiatry, 36(2), 272-281.

Broidy, L. M., Tremblay, R. E., Brame, B., Fergusson, D., Horwood, J. L., Nagin, D. S., et al. (2003). Developmental trajectories of childhood disruptive behaviors and adolescent delinquency: A six-site, cross-national study. Developmental Psychology, 39(2), 222-245.

Buschgens, C. J. M., Swinkels, S. H. M., van Aken, M. A. G., Ormel, J., Verhulst, F. C., \& Buitelaar, J. K. (2009). Externalizing behaviors in preadolescents: Familial risk to externalizing behaviors, prenatal and perinatal risks, and their interactions. European Child \& Adolescent Psychiatry, 18(2), 65-74. 
International Journal of Child, Youth and Family Studies (2011) 1 \& 2: 36-64

Cannon, M., Huttunen, M. O., Tanskanen, A. J., Arseneault, L., Jones, P. B., \& Murray, R. M. (2002). Perinatal and childhood risk factors for later criminality and violence in schizophrenia. The British Journal of Psychiatry, 180(6), 496-501.

Card, N. A., Stucky, B. D., Sawalani, G. M., \& Little, T. D. (2008). Direct and indirect aggression during childhood and adolescence: A meta-analytic review of gender differences, intercorrelations, and relations to maladjustment. Child Development, 79(5), 1185-1229.

Carmichael Olson, H., Streissguth, A. P., Sampson, P. D., Barr, H. M., Bookstein, F. L. \& Thiede, K. (1997). Association of prenatal alcohol exposure with behavioral and learning problems in early adolescence. Journal of the American Academy of Child \& Adolescent Psychiatry, 36(9), 1187-1194.

Cnattingius, S., Lindmark, G., \& Meirik, O. (1992). Who continues to smoke while pregnant? British Medical Journal, 46(3), 218-221.

Connor, P. D., Sampson, P. D., Bookstein, F. L., Barr, H. M., \& Streissguth, A. P. (2000). Direct and indirect effects of prenatal alcohol damage on executive function. Developmental Neuropsychology, 18(3), 331-354.

Conseur, A., Rivara, F. P., Barnoski, R., \& Emanuel, I. (1997). Maternal and perinatal risk factors for later delinquency. Pediatrics, 99(6), 785-790.

Cornelius, M. D., Ryan, C. M., Day, N. L., Goldschmidt, L., \& Willford, J. A. (2001). Prenatal tobacco effects on neuropsychological outcomes among preadolescents. Journal of Developmental and Behavioral Pediatrics: JDBP, 22(4), 217-225.

Côté, S., Vaillancourt, T., LeBlanc, J. C., Nagin, D., \& Tremblay, R. E. (2006). The development of physical aggression from toddlerhood to pre-adolescence: A nationwide longitudinal study. Journal of Abnormal Child Psychology, 34(1), 71-85.

Crepeau-Hobson, M. (2009). The relationship between perinatal risk factors and sensory processing difficulties in preschool children. Journal of Developmental and Physical Disabilities, 21(4), 315-328.

Davie, R., Butler, N., \& Goldstein, H. (1972). From birth to seven: The second report of the National Child Development Study. London: Longman.

Day, N. L., Richardson, G. A., Goldschmidt, L., Robles, N., Taylor, P. M., Stoffer, D. S., et al. (1994). Effect of prenatal marijuana exposure on the cognitive development of offspring at age three. Neurotoxicology and Teratology, 16(2), 169-175.

DeLamater, J., \& Friedrich, W. N. (2002). Human sexual development. Journal of Sex Research, 39(1), 10-14. 
International Journal of Child, Youth and Family Studies (2011) 1 \& 2: 36-64

Dennis, T., Bendersky, M., Ramsay, D., \& Lewis, M. (2006). Reactivity and regulation in children prenatally exposed to cocaine. Developmental Psychology, 42(4), 688-697.

Eiden, R. D., McAuliffe, S., Kachadourian, L., Coles, C., Colder, C., \& Schuetze, P. (2009). Effects of prenatal cocaine exposure on infant reactivity and regulation. Neurotoxicology and Teratology, 31(1), 60-68.

Elliott, D. S. (1994). Serious violent offenders: onset, developmental course, and termination. Criminology, 32(1), 1-21.

Farrington, D. P. (1989). Early predictors of adolescent aggression and adult violence. Violence and Victims, 4(2), 79-100.

Farrington, D. P. (2005). The integrated cognitive antisocial potential (ICAP) theory. In D. P. Farrington (Ed.), Integrated life-course theories of offending: Advances in criminological theory (pp. 73-92). London: Transaction Publishers.

Farrington, D. P., \& Loeber, R. (1998). Major aims of this book. In R. Loeber, \& D. P. Farrington (Eds.), Serious and violent juvenile offenders: Risk factors and successful interventions (pp. 1-10). Thousand Oaks, CA: Sage.

Fergusson, D. M., Horwood, L. J., \& Lynskey, M. T. (1993). Maternal smoking before and after pregnancy: Effects on behavioral outcomes in middle childhood. Pediatrics, 92(6), 815-822.

Fergusson, D. M., Horwood, L. J., \& Northstone, K. (2002). Maternal use of cannabis and pregnancy outcome. BJOG: An International Journal of Obstetrics and Gynaecology, 109(1), 21-27.

Figueredo, A. J., Sales, B. D., Russell, K. P., Becker, J. V., \& Kaplan, M. (2000). A brunswikian evolutionary-developmental theory of adolescent sex offending. Behavioral Sciences \& the Law, 18(2-3), 309-329.

Fox, N. L., Sexton, M., \& Hebel, J. R. (1990). Prenatal exposure to tobacco: I. effects on physical growth at age three. International Journal of Epidemiology, 19(1), 66-71.

Frank, D. A., Bresnahan, K., \& Zuckerman, B. S. (1996). Maternal cocaine use: Impact on child health and development. Current Problems in Pediatrics, 26(2), 57-70.

Fried, P. A., O'Connell, C. M., \& Watkinson, B. (1992). 60- and 72-month follow-up of children prenatally exposed to marijuana, cigarettes, and alcohol: Cognitive and language assessment. Journal of Developmental and Behavioral Pediatrics, 13(6), 383-391.

Fried, P. A., Watkinson, B., Dillon, R. F., \& Dulberg, C. S. (1987). Neonatal neurological status in a low-risk population after prenatal exposure to cigarettes, marijuana, and alcohol. Journal of Developmental and Behavioral Pediatrics, 8(6), 318-326. 
International Journal of Child, Youth and Family Studies (2011) 1 \& 2: 36-64

Fried, P. A., Watkinson, B., \& Gray, R. (1992). A follow-up study of attentional behavior in 6year-old children exposed prenatally to marihuana, cigarettes, and alcohol. Neurotoxicology and Teratology, 14(5), 299-311.

Fried, P. A., Watkinson, B., \& Gray, R. (1998). Differential effects on cognitive functioning in 9- to 12-year olds prenatally exposed to cigarettes and marihuana. Neurotoxicology and Teratology, 20(3), 293-306.

Fried, P. A., Watkinson, B., \& Gray, R. (2003). Differential effects on cognitive functioning in 13- to 16-year-olds prenatally exposed to cigarettes and marihuana. Neurotoxicology and Teratology, 25(4), 427-436.

Friedrich, W. N., Grambsch, P., Broughton, D., Kuiper, J., \& Beilke, R. L. (1991). Normative sexual behavior in children. Pediatrics, 88(3), 456-464.

Friedrich, W. N., Fisher, J. L., Dittner, C. A., Acton, R., Berliner, L., Butler, J., et al. (2001). Child Sexual Behavior Inventory: Normative, psychiatric, and sexual abuse comparisons. Child Maltreatment, 6(1), 37-49.

Glasson, E. J., Bower, C., Petterson, B., de Klerk, N., Chaney, G., \& Hallmayer, J. F. (2004). Perinatal factors and the development of autism: A population study. Archives of General Psychiatry, 61(6), 618-627.

Hardy, J. B., \& Mellits, E. D. (1972). Does maternal smoking during pregnancy have a long-term effect on the child? The Lancet, 300(7791), 1332-1336.

Hodgins, S., Kratzer, L., \& McNeil, T. F. (2001). Obstetric complications, parenting, and risk of criminal behavior. Archives of General Psychiatry, 58(8), 746-752.

Jones, K. L., \& Smith, D. W. (1973). Recognition of the fetal alcohol syndrome in early infancy. The Lancet, 302(7836), 999-1001.

Kershaw, P., Irwin, L., Trafford, K., \& Hertzman, C. (2005). The British Columbia atlas of child development (1st ed.). Victoria, BC: Human Early Learning Partnership and Western Geographical Press.

Knight, R. A., \& Sims-Knight, J. E. (2003). Developmental antecedents of sexual coercion against women: Testing of alternative hypotheses with structural equation modeling. In R. A. Prentky, E. S. Janus, \& M. C. Seto (Eds.), Sexually coercive behavior: Understanding and management (pp. 72-85). New York: New York Academy of Sciences.

Lassen, K., \& Oei, T. P. (1998). Effects of maternal cigarette smoking during pregnancy on longterm physical and cognitive parameters of child development. Addictive Behaviors, 23(5), 635-653. 
International Journal of Child, Youth and Family Studies (2011) 1 \& 2: 36-64

LeBlanc, M., \& Fréchette, M. (1989). Male criminal activity from childhood through youth: Multilevel and developmental perspectives. New York: Springer-Verlag.

LeBlanc, M., \& Bouthillier, C. (2003). A developmental test of the general deviance syndrome with adjudicated girls and boys using hierarchical confirmatory factor analysis. Criminal Behaviour and Mental Health, 13(2), 81-105.

Loeber, R., \& Hay, D. (1997). Key issues in the development of aggression and violence from childhood to early adulthood. Annual Review of Psychology, 48, 371-410.

Loeber, R., \& Stouthamer-Loeber, M. (1998). Development of juvenile aggression and violence: Some common misconceptions and controversies. American Psychologist, 53(2), 242-259.

Loeber, R., Slot, W., \& Stouthamer-Loeber, M. (2008). A cumulative developmental model of risk and promotive factors. In R. N. Loeber, W. Slot, P. H. van der Laan, \& M. Hoeve (Eds.), Tomorrow's criminals: The development of child delinquency and effective interventions (p. 133-161). Farnham, UK: Ashgate.

Lord, C., Mulloy, C., Wendelboe, M., \& Schopler, E. (1991). Pre- and perinatal factors in highfunctioning females and males with autism. Journal of Autism and Developmental Disorders, 21(2), 197-209.

Lösel, F., \& Bender, D. (2006). Risk factors for serious and violent antisocial behaviour in children and youth. In A. Hagell \& J. R. Dent (Eds.), Children who commit acts of serious interpersonal violence: Message for best practice (pp. 42-72). London: Jessica Kingsley Publishers.

Lussier, P., \& Healey, J. (2010). In search of the developmental origins of sexual violence: Examining the co-occurrence of physical aggression and sexual behaviours in early childhood. Behavioral Sciences and the Law, 28(1), 1-23.

Lussier, P., Corrado, R., Healey, J., Tzoumakis, S., \& Deslauriers-Varin, N. (2010). The Cracow instrument for multi-problem violent youth: Examining the postdictive validity with a sample of preschoolers. Manuscript submitted for publication.

Martin, J. C., Barr, H. M., Martin, D. C., \& Streissguth, A. P. (1996). Neonatal neurobehavioral outcome following prenatal exposure to cocaine. Neurotoxicology and Teratology, 18(6), 617-625.

Martin, R. P., Dombrowski, S. C., Mullis, C., Wisenbaker, J., \& Huttunen, M. O. (2006). Smoking during pregnancy: Association with childhood temperament, behavior, and academic performance. Journal of Pediatric Psychology, 31(5), 490-500. 
International Journal of Child, Youth and Family Studies (2011) 1 \& 2: 36-64

Moffitt, T. E. (1993). Adolescence-limited and life course-persistent antisocial behavior: A developmental taxonomy. Psychological Review, 100, 674-701.

Nagin, D. S., \& Tremblay, R. E. (1999). Trajectories of boys' physical aggression, opposition, and hyperactivity on the path to physically violent and nonviolent juvenile delinquency. Child Development, 70(5), 1181-1196.

Nichter, M., Nichter, M. A., Muramoto, M., Adrian, S., Goldade, K., Tesler, L., et al. (2007). Smoking among low-income pregnant women: An ethnographic analysis. Health Education \& Behavior: The Official Publication of the Society for Public Health Education, 34(5), 748-764.

O'Connell, C. M., \& Fried, P. A. (1991). Prenatal exposure to cannabis: A preliminary report of postnatal consequences in school-age children. Neurotoxicology and Teratology, 13(6), 631-639.

Pickett, K. E., Wakschlag, L. S., Dai, L., \& Leventhal, B. L. (2003). Fluctuations of maternal smoking during pregnancy. Obstetrics and Gynecology, 101(1), 140-147.

Randall, C. L., \& Taylor, W. J. (1979). Prenatal ethanol exposure in mice: Teratogenic effects. Teratology, 19(3), 305-311.

Richardson, G. A., \& Day, N. L. (1991). Maternal and neonatal effects of moderate cocaine use during pregnancy. Neurotoxicology and Teratology, 13(4), 455-460.

Richardson, G. A., \& Day, N. L. (1994). Detrimental effects of prenatal cocaine exposure: Illusion or reality? Journal of the American Academy of Child \& Adolescent Psychiatry, 33(1), 28-34.

Rowe, D. C., Vazsonyi, A. T., \& Figueredo, A. J. (1997). Mating-effort in adolescence: A conditional or alternative strategy. Personality and Individual Differences, 23(1), 105-115.

Schoentjes, E., Deboutte, D., \& Friedrich, W. (1999). Child sexual behavior inventory: A Dutchspeaking normative sample. Pediatrics, 104(4), 885-893.

Sexton, M., Fox, N. L., \& Hebel, J. R. (1990). Prenatal exposure to tobacco: II. Effects on cognitive functioning at age three. International Journal of Epidemiology, 19(1), 72-77.

Spinillo, A., Montanari, L., Gardella, B., Roccio, M., Stronati, M., \& Fazzi, E. (2009). Infant sex, obstetric risk factors, and 2-year neurodevelopmental outcome among preterm infants. Developmental Medicine and Child Neurology, 51(7), 518-525.

Streissguth, A. (2007). Offspring effects of prenatal alcohol exposure from birth to 25 years: The Seattle prospective longitudinal study. Journal of Clinical Psychology in Medical Settings, 14, 81-101. 
International Journal of Child, Youth and Family Studies (2011) 1 \& 2: 36-64

Streissguth, A. P., Barr, H. M., \& Sampson, P. D. (1990). Moderate prenatal alcohol exposure: Effects on child IQ and learning problems at age 7 1/2 years. Alcoholism, Clinical and Experimental Research, 14(5), 662-669.

Streissguth, A. P., Barr, H. M., Sampson, P. D., \& Bookstein, F. L. (1994). Prenatal alcohol and offspring development: The first fourteen years. Drug and Alcohol Dependence, 36(2), 89-99.

Streissguth, A. P., Grant, T. M., Barr, H. M., Brown, Z. A., et al. (1991). Cocaine and the use of alcohol and other drugs during pregnancy. American Journal of Obstetrics and Gynecology, 164(5), 1239-1243.

Sun, J., Mohay, H., \& O'Callaghan, M. (2009). A comparison of executive function in very preterm and term infants at 8 months corrected age. Early Human Development, 85(4), 225-230.

Sykes, D. H., Hoy, E. A., Bill, J. M., McClure, B. G., Halliday, H. L., \& Reid, M. M. (1997). Behavioural adjustment in school of very low birthweight children. Journal of Child Psychology and Psychiatry, and Allied Disciplines, 38(3), 315-325.

Thornberry, T. P. (2005). Explaining multiple patterns of offending across the life course and across generations. Annals of the American Academy of Political and Social Science, 602(1), 156-195.

Tibbetts, S. G., \& Piquero, A. R. (1999). The influence of gender, low birth weight, and disadvantaged environment in predicting early onset of offending: A test of Moffitt's interactional hypothesis. Criminology, 37(4), 843-878.

Tremblay, R. E. (2003). Why socialization fails? The case of chronic physical aggression. In B. B. Lahey, T. E. Moffitt, \& A. Caspi (Eds.), Causes of conduct disorder and juvenile delinquency (pp. 182-224). New York: Guilford Publications.

Tremblay, R. E., Japel, C., Pérusse, D., McDuff, P., Boivin, M., Zoccolillo, M., et al. (1999). The search for the age of 'onset' of physical aggression: Rousseau and Bandura revisited. Criminal Behaviour and Mental Health, 9(1), 8-23.

Tremblay, R. E., Nagin, D. S., Séguin, J. R., Zoccolillo, M., Zelazo, P. D., Boivin, M., et al. (2004). Physical aggression during early childhood: Trajectories and predictors. Pediatrics, 114(1), 43-50.

Weissman, M. M., Warner, V., Wickramaratne, P. J., \& Kandel, D. B. (1999). Maternal smoking during pregnancy and psychopathology in offspring followed to adulthood. Journal of the American Academy of Child and Adolescent Psychiatry, 38(7), 892-899. 
International Journal of Child, Youth and Family Studies (2011) 1 \& 2: 36-64

Wingerd, J., \& Schoen, E. J. (1974). Factors influencing length at birth and height at five years. Pediatrics, 53(5), 737-741.

Zwaigenbaum, L., Szatmari, P., Jones, M. B., Bryson, S. E., MacLean, J. E., Mahoney, W. J., et al. (2002). Pregnancy and birth complications in autism and liability to the broader autism phenotype. Journal of the American Academy of Child and Adolescent Psychiatry, 41(5), 572-579. 